\title{
Climate Change: From Copenhagen to Cancun and Thereafter
}

\author{
Badar Alam Iqbal \\ UGSM-Monarch Business School \\ Monarch University, Switzerland \\ \& \\ Munir Hassan \\ Department of Business Administration \\ Allen University, USA
}

\begin{abstract}
Climate change has become the most challenging problem and task for every one living on the earth. The most unfortunate thing is that neither the developed countries nor the developing economies are serious on this task and as a result, on concrete solution has come so far. There has been more myth rather reality. As the time running very fast, it has become imperative for those economies which are major player in the issue of climate change must come forward with a concrete solution to this problem at all costs. Otherwise, the globe will have to face irrecoverable damages and every one will have to bear the unimaginable loss of humanity and materials. The present paper analyses the major issues taken at Copenhagen and Cancun. How far the decisions taken at Copenhagen have been implemented and what is to be decided at Cancun. The paper also suggests what should be done after the Cancun meet for meeting the rising challenges of climate change.
\end{abstract}

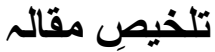

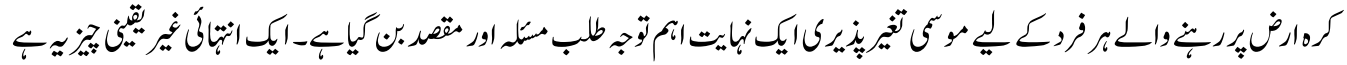

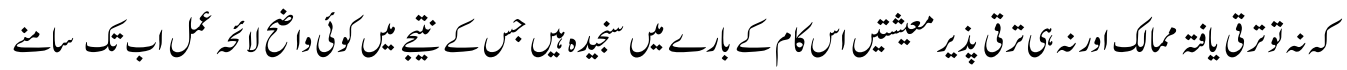

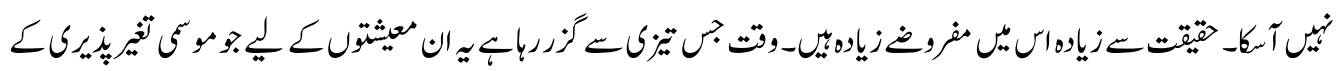

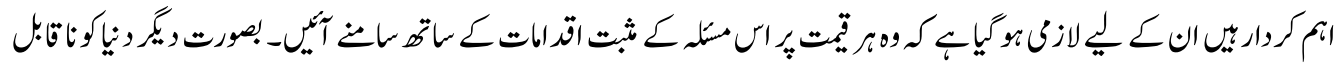

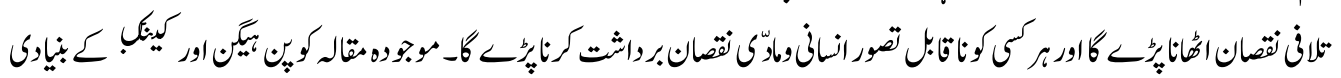

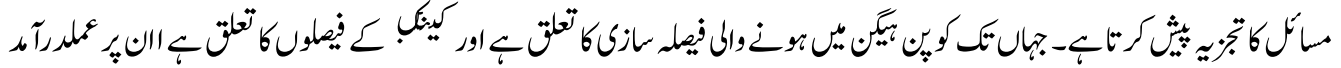

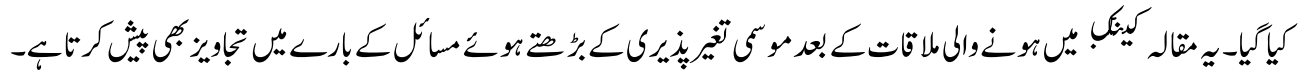

Key Words: Kyoto Protocol, Bali Action Plan, Copenhagen Accord, global community, Mitigation, and Cancun summit. 


\section{Introduction}

The frequency of extreme climate events, trends, their magnitude and extent are rapidly rising and hence, there are enough bases for strong measures to enforce mitigation and adaptation steps to save earth from further decay or damage. The researches and the case studies over the past ten years or a decade have concentrated on the relationship between climate change and frequency, magnitude and the extent of extreme events. The findings are consistent with the first report of Inter-governmental Panel on Climate Change (IPCC) submitted in 1990. This very observation could be tested from the fact that the decade of 90s was less warm than the decade of 2000s (Asrar 2009). The decade of 70s was much less warmer than the decade of 80s.

\section{Harsh Facts}

In the year 1985, for the first time major climate change summit had estimated 19.6 billion tons global carbon dioxide emission and also warned that greenhouse gases would increase global temperature and may cause sea levels to increase by as much as one meter by 2050 .

In 1988, United Nations created Inter-governmental Panel on Climate Change (IPCC) to examine and submit report on global warming. In 1990, first ICC Report pointed out that globe has warmed by 0.5 degree $C$ over past Century and future warming may be likely.

In 1992, Framework Convention on Climate Change (FCCC) had fixed a target of reducing emissions from industrialized countries to 1990 levels by year 2000. The target was fixed on the basis of RIO Agreement signed by 154 economies.

In 1995, first FCCC Conference known as COP 1 took place in Berlin (Germany). Second IPCC Report indicated that global temperature could go up to 3.5 degree $\mathrm{C}$ by the end of the present Century i.e. $21^{\text {st }}$ Century.

Kyoto Protocol was signed among the countries and for the first time it was legally binding that emissions must cut by industrialized countries to the extent of 5.2 per cent by the end of 2012 . The most noticeable feature is that US President Mr. Bill Clinton signed the Kyoto Protocol but the US Senate had refused to ratify it. ${ }^{1}$ The year 1998 was recorded as the hottest year on the earth.

In 2000, IPCC scientists had given another warning that globe would become warmer by 6 degree $\mathrm{C}$ by the end of the present Century. In 2001, third IPCC Report communicated an unprecedented global warming. Accordingly, the then US President Mr. George Bush renounces Kyoto Protocol claiming it would damage economy.

European Union (EU), Japan and others in 2002 ratify Kyoto Protocol. But Australia joined the US in refusing the Protocol. In order to make it legally binding the agreement or treaty 
should have been signed by at least 55 nations. Russia was left out to make or break the agreement as it was bit hesitant in ratifying the treaty.

In 2003, deadly summer heat wave in Europe was experienced and resulted into 30,000 deaths. Scientists were uncertain it is blip or new, more ominous trend. In 2004, Russia's President Mr. Vladimir Putin backed the Kyoto Protocol and accordingly, in 2005 the Kyoto Protocol came into effect.

Fourth IPCC Report was published in 2007 and the main prediction was that Himalayan Glaciers would melt by 2035 and this prediction was based on anecdotal evidence.

In 2009, hacked e-mail from University of East Angila cast doubt and shadow over climate change science. Copenhagen Climate Change Summit-COP 15 failed to get fresh deal needed before Kyoto Protocol which is going to expire at the end of 2012 (Menon, 2010).

\section{Who are the Worst Affected Nations?}

Poorer developing countries are often hit much harder. These results underscore the vulnerability of poor countries to climatic risks, despite the fact that the absolute monetary damages are much higher in richer countries.

The Climate Risk Index ranks nations that have been worst affected by climate change and are most vulnerable to global warming on the basis of an (Climate Risk Index) CRI score. The criterion followed in constructing index is "the lower the score on the index, the higher the risk to that country". In all, 654 events were registered worldwide which caused nearly 93,700 deaths and economic losses of more than US $\$ 123$ billion. Only around a third had been insured, primarily in developed countries. The fact that no further peak catastrophe has happened in Bangladesh, like in 1991 when 140,000 people died, is partial proof that it is possible to better prepare for climate risks and prevent larger-scale disasters. The following are the countries having noticeable facts:

Bangladesh has been the most affected country by extreme weather conditions. And globally, in the last 18 years, extreme weather conditions have killed 600,000 people and cost a loss of $\$ 1.7$ trillion, according to German watch's Global Climate Risk Index 2010. In Myanmar, more than 95 per cent of the damages and fatalities occurred because of cyclone Nargis. Cyclone Nargis killed as many as 100,000 people. One million people were rendered homeless. Many towns and villages were been washed away. Climate Risk Index (CRI) score: 8.25; Annual death toll due to extreme climate: 4,522; Total losses: $\$ 707$ million; and losses per unit of Gross Domestic Product (GDP): 2.55 per cent. Honduras has been hit by severe tropical storms and hurricanes over the years. Hurricane Mitch, which hit the country, changed the landscape of Honduras. About 200,000 people were affected by severe flooding 
caused by heavy rains, and 20,000 people have been forced to flee their homes. Climate Risk Index (CRI) score: 12.00; Annual death toll due to extreme climate: 340; Total losses: $\$ 660$ million; Losses per unit of Gross Domestic Product (GDP): 3.37 per cent. Vietnam: Over the last decade, the frequency and severity of droughts and floods have intensified, increasing their impact on living conditions. Many people have been affected by cyclones and hailstorms. Climate Risk Index (CRI) score: 18.83; Annual death toll due to extreme climate: 466; Total losses: \$1,525 million; Losses per unit of Gross Domestic Product (GDP): 1.3 per cent. Nicaragua: Nicaragua has been often hit by earthquakes, hurricanes, floods and volcano eruptions. Climate Risk Index (CRI) score: 21; Annual death toll due to extreme climate: 164; Total losses: \$211million; Losses per unit of Gross Domestic Product (GDP): 2.0 per cent. Haiti: Four storms -- Fay, Gustav, Hanna, and Ike -- devastated this poverty-struck nation. About 800,000 people were affected in 2008. Haiti's poverty, weak infrastructure, vulnerable environment and fiscal problems worsen the impact of a natural disaster. Climate Risk Index (CRI) score: 22.83; Annual death toll due to extreme climate: 335; Total losses: $\$ 95$ million; Losses per unit of Gross Domestic Product (GDP): 1.08 per cent. India: Natural disasters have caused extensive damage to India over the years. Droughts, flash floods, cyclones, avalanches, landslides brought on by torrential rains, and snowstorms pose the greatest threats. Floods are the most common natural disaster in India. China, India, Bangladesh and the Philippines belong to those countries that are most often hit by extremes which, of course, are partially due to their large size and/or specific exposure to extreme weather events, the study states. Climate Risk Index (CRI) score: 25.83; Annual death toll due to extreme climate: 3,255; Total losses: $\$ 6,132$ million; Losses per unit of Gross Domestic Product (GDP): 0.3 per cent. Philippines: A disaster-prone country, the Philippines is recurrently hit by natural disasters: typhoons, earthquakes. The Philippines faces on average 20 typhoons each year. Climate Risk Index (CRI) score: 27.67; Annual death toll due to extreme climate: 799; Total losses: $\$ 544$ million; Losses per unit of Gross Domestic Product (GDP): 0.30 per cent. China: China is one of the country's most affected by natural disasters. It had 6 of the world's top 10 deadliest natural disasters, which include floods, droughts, ecological disasters, and forest and grassland fires. China had been badly hit by Typhoon Hagupit. About 70,000 people were killed and 18,000 people were reported missing after a 7.9-magnitude earthquake struck Sichuan. Climate Risk Index (CRI) score: 28.58; Annual death toll due to extreme climate: 2,023; Total losses: $\$ 25,961$ million; Losses per unit of Gross Domestic Product (GDP): 0.78 per cent. 
The Year 2010 was the one of the Hottest Years (Chart 1)

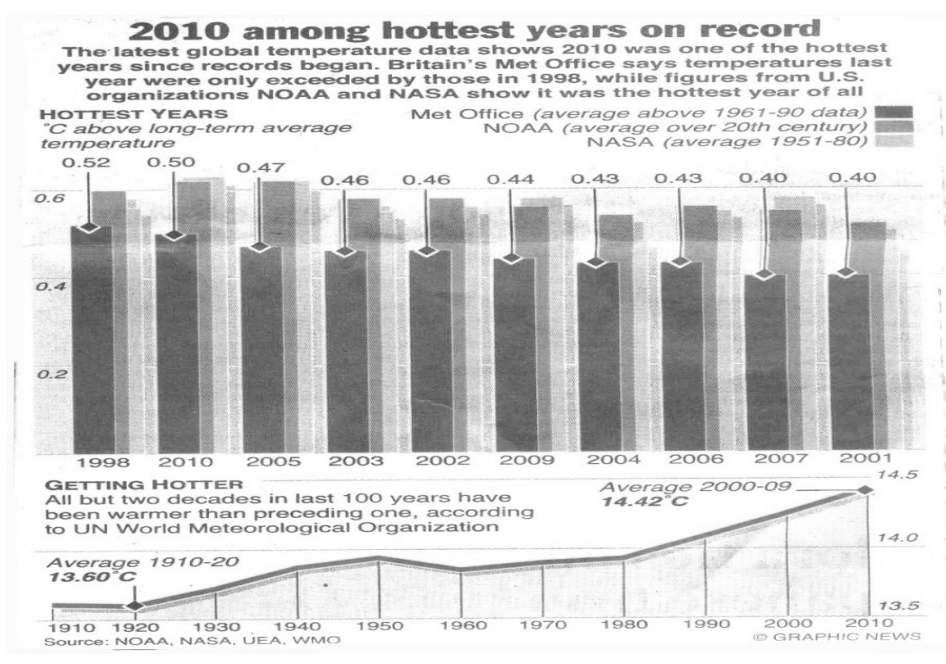

\section{Copenhagen Summit}

The $15^{\text {th }}$ Conference of Parties popularly known as COP-15 of the United Nations Framework Convention on Climate Change (UNFCCC) attracted the attention of the whole globe. Ten thousands delegates, observers and activists marched on the streets descended upon Copenhagen, while many millions followed proceedings around the planet through media and cyberspace.

Since the Copenhagen summit concluded with a non-binding agreement, negotiators were unable to bridge the divide between richer countries bound by Kyoto Protocol and poor nations led by China and India that reject rules for their industrialized nations. A year ago (2009) in Copenhagen delegates failed to draft a treaty, leaving in limbo the 1997 Kyoto accord that mandated cuts in carbon-dioxide emissions until the end of 2012.

There were high hopes and expectations that 'political agreement' would be clinched for the Bali Action Plan and through an appropriate legal instrument and the Kyoto Protocol sealed. This was how the globe would begin to move towards a climate safe future based upon cooperation and solidarity of nations developed and developing, big and small. The contours of such an effect were well known and much discussed. An unprecedented number of heads of States- more 100 were expected to have been prepared by their respective negotiators and Ministers before they were to arrive in Copenhagen. This happy and fruitful end however, did not happen and materialize. $^{2}$ 
The negotiators did not sum up their respective deliberations; the Ministers who arrived at Copenhagen a little earlier than their respective heads of States also did not make any noticeable progress either, leaving the heads of States to wade through a maze of contentious issues that have bedevilled climate deliberations since Bali.

At the heart of the deadlock in the deliberations were divergence of opinion between the developed and developing- big or small, vulnerable, capable and not so capable nations in respect of their respective role and responsibilities to deal with climate change and global warming. According to the Framework agreed to under the Bali Action Plan, that was based upon the 'principle of common but differentiated responsibilities', the rich developed nations were to substantially reduce their respective emissions at least by a margin of 40 per cent below 1990 levels by 2020 as suggested by the latest scientific evidence and opinion and demanded by the small islands states. The support developing economies actions for enhanced implementation of the UNFCCC through transfer of adequate finances and environmentally sound technologies did not fructify. A concerted global and equitable effort and collaborative approach, the globe could avoid catastrophic climate change by limiting the rise of global temperatures to within 2 degrees Celsius. This hope and high expectations were frustrated at Copenhagen.

The upshot that after two years of deliberations since COP 13 at Bali was the Copenhagen Accord, it was not a legally binding treaty since COP 15 only took note of it and did not adopt it as a decision. Added to this, there was fierce opposition to its adoption from group of small and vulnerable nations. It was negotiated by a small Group of countries from among the 192 nations that are the parties to UNFCCC and then was sought to be imposed upon the others. In itself it was an outcome of a flawed negotiating process. Further to the process of formulation, the Copenhagen Accord does not reflect a global aspiration in terms of concrete steps or measures that would avoid catastrophic global warming or climate change.

In terms of negotiations, the Copenhagen conference was close to an agreement on reducing emissions from deforestation and forest degradation along with adaptation and technology transfer. But the only question was how much money was available or would be provided by the developed nations. A positive outcome was that for the first time, US $\$ 30$ billion was promised for 2010-12 (Haq, 2010).

The so called 'fast start finance' was intended to help developing nations, in particular the poorest and the most vulnerable, reduce their greenhouse emissions (Chart) and adapt to the effects of climate change. Further the Copenhagen Accord mandated that fast start funds have a 'balanced allocation between mitigation and adaptation' and 'new and additional'. Fast start adaptation funding was particularly crucial for poor countries facing rapid climate change. ${ }^{3}$ The 
promised Green Fund could be materialized sooner or the later. The US had a strong preference for routing funds outside the preview of UNFCCC. The developed nations had a mental frame for assistance-it was a paradigm of charity still. However, it was important to understand that this was an agreement where the recipients had a say and it was not charity.

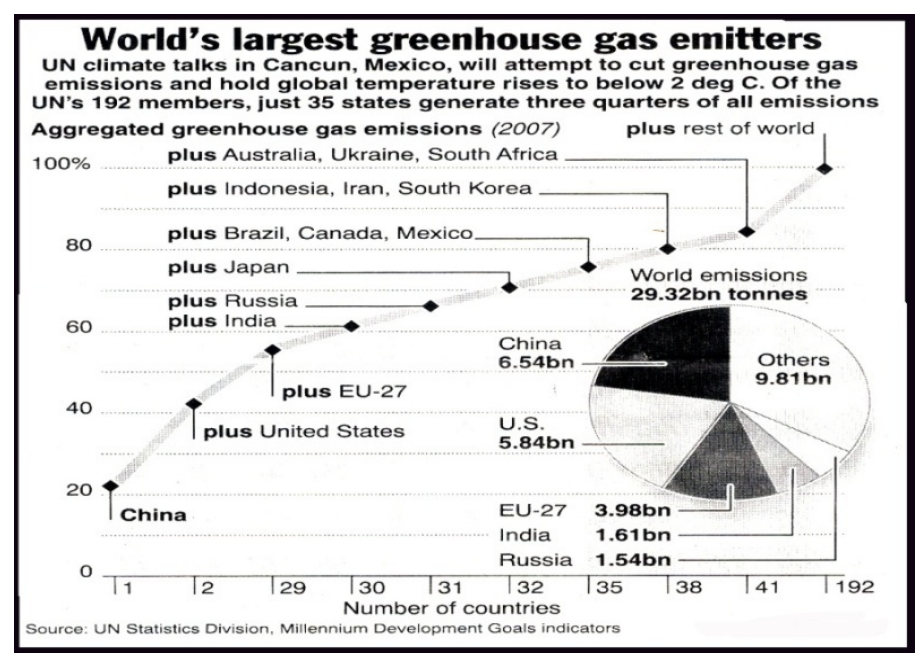

So far pledges of money for adaptation from developed nations have been inadequate (Haq, 2010). At the end of October 2010, donors have pledged highly variable amounts and types of funding and have set aside only a slim portion for adaptation. According to an analysis, only nearly US \$ 3.14 billion has been formally allocated for adaptation. There is also a danger that this could come in the form of loans which would further indebt already poor countries. Of the total amount of US \$ 28.46 billion fast-start funds pledged so far, adaptation funding accounts only between 11 and 16 per cent, which is clearly far from a 'balanced' financing of adaptation measures. It is imperative to point out here that during climate change deliberations, poor economies have consistently stressed the need for high levels of adaptation funding. Many developed nations have not provided details of how their respective pledges would be realized. For instance, Belgium, Finland and France have not indicated their respective proposed share of adaptation funds. Assuming that these countries allocate 50 per cent of their respective pledges to adaptation-as per the Copenhagen Accord mandate, the total adaptation funds add up to only US $\$ 4.5$ billion i.e. 15 per cent of the all fast-start funds pledged.

Similarly a number of pledges are not 'new and additional'. These are renamed commitments made earlier either under Official Development Assistance (ODA) or other. For example, the US (adaptation component 33.8 per cent) and the UK (13.5 per cent) have counted their previous commitments to Climate Investment Funds (CIF) as part of fast-start finance pledge. More significantly, most of the donors have not specified how they would channel the fast-start funds. 
Only US \$ 250.7 million has been designated to be delivered through United Nations Framework Convention on Climate Change (UNFCCC) channels. Of this, the UNFCCC adaptation Fund specifically has received only US \$ 79.9 million in pledges. Large amounts have, however, already been directed to the World Bank and other agencies controlled mainly by the developed nations.

This is contrary to the Copenhagen Accord which promised delivery of adaptation funds through mechanism whole governance would give equal representation to developed and developing nations.

\section{Cancun Summit}

From Bali in Indonesia (2007), to Poznan in Poland (2008), to Copenhagen in Denmark (2009) and Cancun in Mexico (2010), is our last chance to save earth. Since 2007 (Bali) developed and developing nations have been struggling to fix desired levels of carbon emission cuts that each other should adopt to ensure that world average temperature dos not rise beyond 2 degree Celsius (preferably, 1.5 degree Celsius) by 2050 that is sine-quo-non to save the globe from calamity (Sangal, 2010).

In view of existing grim scenario, it cannot be hoped that any universally acceptable solution at Cancun unless there is a change in strategy in regard to combating climate change. For this, there is an immediate need of paradigm shift in thinking and practices.

Cancun was all about money. There are two vital and strategic issues to be looked into at Cancun. First, how much total investment is required at the global level for Research and Development (R \& D). Second, who should fund this research? These needs of funds require to be calculated carefully by experts. It has been estimated that an amount of 0.2 per cent of global GDP that comes nearly US $\$ 100$ annually till 2050 would be needed for R and D. This is well within the capabilities of G-20 Group of world's richest nations that constitute 90 per cent of the world's earnings. This in fact not an insurmountable amount if there is a serious desire to mitigate global warming.

At Cancun there are two broad camps. On the one hand there is the absolutist camp, which advocates for one big package and nothing else. On the other side, there is the incrementalist camp, which is more pragmatic and believes in that something achieved is better than nothing. Whereas industrial nations are more interested in mitigating the impact of climate change, developing economies are keener on funds to help them adapt to it. The "doable" at Cancun are funds for adaptation, for reducing deforestation and facilitating transfer of environment friendly technologies (Monte, 2010).

Where these funds would go to remain under reported and unexplained. Every developed nation had its own agencies namely- USAID (USA) and DFID (UK). The second priority would be 
multilateral agencies like the World Bank. The UN agencies would come last for technology transfer and adaptation. Developing countries want this funding in the reverse order i.e. UN agencies, World Bank and USAID and DFID.

It is true to say that at Cancun, the principle of natural justice is to be followed. Climate change is not a matter of distribution of funds to any one the donor decides, but should adhere to the polluter pays. It must be treated as compensation to the victims not as an aid envisaged by the developed nations.

The COP-15 had created an atmosphere of distrust between developed and developing countries still persisting, the Cancun summit or COP-16 should bring some dent in the trust deficit otherwise Cancun may go Copenhagen way which would be the biggest disaster on the planet and consequences, effects, impact and implications would be unbearable.

\section{Thereafter}

If any concrete agreement or treaty does not come out at Cancun, then the only option left out for 193 countries is to give momentum to smaller agreements than a big one. Government should do a lot more to size opportunities to lower both costs and emissions also and to enhance the competitiveness of their respective economies in the process.

\section{End Notes}

1. Extreme Climate Events in Store; the Hindu; Chennai; December 2, 2010. P. 9

2. Copenhagen Accord of and For Rich Developed Countries; Monthly Commentary; New Delhi; January 2010; P. 3.

\section{References}

Asrar, G.R. (2009) Director, World Climate Research Programmed; United Nations; Geneva; Switzerland; (Conference Address)

Copenhagen Accord of and For Rich Developed Countries; Monthly Commentary; New Delhi; January 2010; P. 3.

Extreme Climate Events in Store; The Hindu; Chennai; December 2, 2010. P. 9. 
Haq, S. (2010) Institute Report; Senior Fellow; International Institute for Environment and Development; London; March, 2010.

Monte, D (2010) Climate Talks Looking for International Commitment; The Hindustan Times; New Delhi; November 30, P. 11.

Menon, M (2010) Agreement on New Emission Cut; The Hindu; Chennai; November 20, 2010; P. 11

Sangal, P.P (2010) Achieving Success at Cancun; The Economic Times; New Delhi; November 29, P. 10

Whither Copenhagen Promise of Funding Developing Countries; The Hindu; Chennai; November 18, 2010; P. 13.

World Resources Institute; Geneva; Switzerland; Annual Report; May 2010.

Prof. Dr. Badar Alam Iqbal is Adjunct Professor in the UGSM-Monarch Business School Monarch University, Switzerland.

Prof. Dr. Munir Hassan is associated with Department of Business Administration, Allen University, Columbia (South Carolina) USA. 